\title{
Fascistas y antifascistas en las elecciones de la Sociedad Italia Unita de Bahía Blanca (enero de 1927)
}

\author{
Fascists and antifascists \\ in the elections of the Italia Unita Society \\ of Bahía Blanca (January 1927)
}

\author{
Bruno Cimatti \\ Centro de Estudios Regionales "Félix Weinberg" \\ Centro de Estudios del Siglo XX \\ Universidad Nacional del Sur \\ (Argentina) \\ bgcimatti@gmail.com
}

\begin{abstract}
En este artículo buscamos reconstruir el conflicto entre fascistas y antifascistas en las elecciones de la Sociedad Italia Unita de Bahía Blanca, realizadas el 16 de enero de 1927, a partir de la amplia difusión que tuvieron en las páginas de la prensa local. Tales comicios revistieron un carácter abiertamente político, teniendo en cuenta que desde el 15 de mayo de 1926 operaba en la ciudad el fascio "Giulio Giordani", institución que desde sus orígenes buscaba erigirse en representante de la comunidad italiana de la ciudad. En ese contexto, las elecciones de la Sociedad italiana fueron la manifestación institucional del conflicto que, desde la constitución del fascio, se daba entre sus miembros y los antifascistas locales, muchos de ellos ligados al Centro Socialista de Bahía Blanca. Se ensayará, entonces, una interpretación de las elecciones (así como de su clima de campaña previo y sus consecuencias) a la luz de la disputa entre fascismo y antifascismo por la hegemonía en la colectividad italiana bahiense. El trabajo se enmarca en una investigación más amplia que busca analizar, en el caso bahiense, los resultados del intento de controlar las instituciones italianas en el extranjero por parte del gobierno italiano.
\end{abstract}

Palabras Clave: Fascismo - Antifascismo - Bahía Blanca - Asociacionismo - Colectividad italiana 


\begin{abstract}
The aim of this article is to reconstruct the conflict between fascists and antifascists during the elections celebrated in the Italia Unita Society of Bahía Blanca, on January 16th 1927, through the wide broadcasting it had in the local press. These elections showed an openly politic nature, having into account the fact that the fascio 'Giulio Giordani' operated in the city, since May $15^{\text {th }} 1926$. This institution, since its very origins looked for becoming the representative of the local Italian community. In that context, the elections in the Italian entity were an institutional manifestation of the conflict that, since the constitution of the fascio, existed between its members and local antifascists, many of them linked to the Socialist Center of Bahía Blanca. Then, our study attempts to understand the elections - as well as the atmosphere during the election campaign, and fundamentally its consequences- in the light of the dispute between fascism and antifascism for the hegemony in the Italian community of Bahía Blanca. This paper belongs to a wider investigation that searches to analyze, for the case of Bahía Blanca, the results of the Italian government's attempt to control the Italian institutions abroad.
\end{abstract}

Key Words: Fascism - Antifascism - Bahía Blanca - Associationism - Italian community

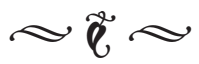

\section{Introducción}

En este artículo buscamos reconstruir el conflicto entre fascistas y antifascistas en las elecciones de la Sociedad Italia Unita de Bahía Blanca, realizadas el 16 de enero de 1927. Tales comicios fueron los primeros desde la fundación, el 15 de mayo de 1926, del fascio "Giulio Giordani", cuya presencia como institución que buscaba erigirse en representante de la comunidad italiana local introdujo la disputa entre fascismo y antifascismo en la realidad bahiense. En ese contexto, las elecciones de la entidad italiana fueron la manifestación institucional del conflicto que, desde la constitución del fascio, se daba entre sus miembros y los antifascistas locales, muchos de ellos ligados al Centro Socialista de Bahía Blanca (CSBB).

Como veremos, las instituciones italianas de la era liberal fueron un blanco del fascismo 118 en el exterior, lo que motivó conflictos por el control de las mismas con los sectores que, en el extranjero, se oponían al gobierno italiano. Es por esto que las elecciones del 16 de enero de 1927 fueron un hecho trascendental que, lejos de significar una simple elección de renovación de autoridades, simbolizó en el nivel institucional la disputa entre fascistas y antifascistas por la hegemonía dentro de la importante colectividad italiana bahiense. ${ }^{1}$ Este estudio se realiza en el marco de una investigación más amplia, que pretende analizar, en el caso bahiense, los resultados del intento por parte del gobierno italiano de ejercer su control sobre las instituciones surgidas en el extranjero durante los años de la Italia liberal.

1. En 1914, según el tercer Censo Nacional, la ciudad de Bahía Blanca contaba con 62.191 habitantes. De ellos 12.257 eran italianos, siendo la segunda colectividad en importancia detrás de los españoles (13.374). 
Para nuestro análisis nos valdremos de la profusa difusión que las elecciones tuvieron en la prensa comercial de la ciudad, a través de las páginas de los dos principales diarios de la época, La Nueva Provincia y El Atlántico. A su vez, el periódico bisemanal Nuevos Tiempos, órgano de prensa del CSBB, permite recoger informaciones que, soslayadas por la prensa comercial, cobran especial significado desde una mirada política partidaria. Estas fuentes permiten reconstruir el ambiente vivido en la ciudad antes, durante y después de las elecciones, así como el accionar de ambas listas rivales durante la campaña. Por último, el relevamiento de las actas de la Sociedad Italia Unita, realizado por Geremia Crocitto (miembro de trayectoria dentro de la colectividad italiana) en su reconstrucción de la historia del primer centenario de la Sociedad Italiana de Socorros Mutuos de Bahía Blanca, permite un acercamiento institucional al tema que nos interesa.

Es oportuno realizar aquí un breve comentario sobre las fuentes a utilizar, ya que no debe desatenderse el rol de la prensa como actor político. En el caso que analizamos, tanto los diarios La Nueva Provincia y El Atlántico como el periódico Nuevos Tiempos se involucraron profundamente en la contienda electoral por la dirección de la Sociedad Italia Unita. Si en el caso de Nuevos Tiempos su acción política fue más explícita por su carácter partidario, creemos necesario introducir una breve reflexión sobre las otras dos publicaciones referidas, a partir del estudio realizado por Cernadas y Orbe sobre la prensa de Bahía Blanca. ${ }^{2}$ La Nueva Provincia, diario fundado

2. CERNADAS, Mabel y ORBE, Patricia, "Diarios bahienses en perspectiva: idas y vueltas en búsqueda de la pluralidad", en CERNADAS, Mabel y ORBE, Patricia (compiladoras) Itinerarios de la prensa: cultura política por Enrique Julio en 1898, buscó generar una imagen de objetividad y profesionalismo periodístico, ajeno a las disputas políticas, y se convirtió con el correr del tiempo en uno de los matutinos de mayor circulación en la provincia de Buenos Aires. Por su parte, El Atlántico, fundado en 1920 bajo la dirección de Edmundo Calcagno, fue consolidándose como el principal competidor de La Nueva Provincia. Lo que nos interesa aquí es el hecho subrayado por las autoras de que, en la época, se iba perfilando en ambas publicaciones un perfil empresarial que, por su carácter profesional, moderado e independiente, las diferenciaba de aquellas que eran sostenidas por partidos políticos. Sin embargo, esto no significa que esos diarios no tuvieran una participación política en la contienda, particularmente $L a$ Nueva Provincia, que en ningún momento ocultaría su simpatía por la lista ligada al fascio local. En este sentido, es lícito realizar una crítica a las fuentes entendiendo que la información presentada puede ser tendenciosa en tanto las direcciones de las publicaciones seguían sus propios intereses y simpatías políticos. No obstante, creemos que, aun así, tienen mucho que aportar, en especial a la reconstrucción del clima político en que se desarrollaron los comicios que estudiamos.

Consideramos que la importancia del análisis de las elecciones en la Sociedad Italia Unita reside en el carácter simbólico que tuvo en su época, cuando fascistas y antifascistas transportaban a la ciudad la polarización política que el régimen de Mussolini había generado en los italianos del mundo, y aun fuera de los confines de las colectividades de ese origen. Es necesario entonces, analizar

y representaciones en Babia Blanca durante el siglo XX, Ediuns, Bahía Blanca, 2013. 
la disputa entre fascismo y antifascismo intentando problematizar sus manifestaciones locales, en vistas de su complejidad en un contexto tan distinto del italiano.

\section{El conflicto fascismo-antifascismo en la Argentina ${ }^{3}$}

La mayoría de los estudios realizados sobre el conflicto entre fascismo y antifascismo en la Argentina se enfocan principalmente en la década de 1930, fundamentalmente, porque realizan una aproximación desde el antifascismo argentino, cuyo principal desarrollo se dio a mediados de dicha década por la conjunción de tres factores: el avance del nacional-socialismo en Alemania desde 1933, la eclosión de la idea de Frente Popular a partir de 1935, y el desarrollo de la Guerra Civil Española desde $1936 .{ }^{4}$

3. No incluiremos aquí, por razones de extensión, un análisis de los numerosos estudios sobre este conflicto en otros países con colectividades italianas significativas, entre ellos, CRESCIANI, Gianfranco, Fascism, Antifascism, and Italians in Australia, 1922-1945, Australian National University Press, Canberra, 1980; BEZZA, Bruno, Gli italiani fuori d'Italia: gli emigranti italiani nei movimienti operai dei paesi d'adozione, 1880-1940, Franco Agneli, Milano, 1983; BRUTI LIBERATI, Luigi, Il Canada, l'Italia e il fascismo, 1919-1945, Bonacci, Roma, 1984; MORELLI, Anne, Fascismo e antifascismo nell'emigrazione italiana in Belgio (1922-1940), Bonacci, Roma, 1987; ALDRIGHI, Clara, Antifascismo italiano en Montevideo: El diálogo politico entre Luigi Fabbri y Carlo Rosselli, Universidad de la República, Montevideo, 1996; BERTONHA, João Fábio, Sob a sombra de Mussolini: os italianos de Sao Paulo e a luta contra o fascismo, 1919-1945, FAPESP, Sao Paulo, 1999.

4. BISSO, Andrés, "El antifascismo latinoamericano: usos locales y continentales de un discurso europeo", en Asian Journal of Latin American Studies, Daegu, 2000, V. XXVI, No 2, pp. 91-116; BISSO, Andrés, "El antifascismo argentino: imagen de redención 'democrática' de la sociedad civil en la Argentina fraudulenta y militar de
Distintos autores analizan cómo estos elementos favorecieron la traslación al ámbito nacional de una contienda que comenzaba a desarrollarse a nivel mundial, convirtiéndose los términos fascismo y antifascismo en conceptos utilizables en las discusiones políticas fuera de Europa..$^{5}$ En este sentido, se erigiría lo que Pasolini denomina "cultura antifascista", articulando distintas matrices ideológicas presentes en la Argentina, desde la liberal hasta la marxista, que crearon un marco para interpretar en clave antifascista los acontecimientos políticos tanto en Europa como en la Argentina. ${ }^{6}$ Puede introducirse aquí la idea de Bisso de un antifascismo despojado de su impronta "heroica", concebido como una herramienta política para la defensa de intereses locales concretos, idea que será de utilidad para interpretar el caso abordado. ${ }^{7}$

Con todo, la idea común en la historiografía

los años 30 y 40", en Trabajos y Comunicaciones, La Plata, 2000, No 26-27, pp. 211-232; PASOLINI, Ricardo, "Intelectuales antifascistas y comunismo durante la década de 1930. Un recorrido posible: entre Buenos Aires y Tandil", en Estudios Sociales, Santa Fe, 2004, V.XXVI, No 1, pp. 81-116; ARDANAZ, Eleonora, "Pelando papas se combate al fascismo: roles y funciones de las asociaciones antifascistas de Bahía Blanca durante la Guerra Civil Española", en Cuadernos de H Ideas, La Plata, 2013, V. VII, No 7; BORDAGARAY, María Eugenia, "Luchas antifascistas y trayectorias generizadas en el movimiento libertario argentino (1936-1955)", en Cuadernos de H Ideas, La Plata, 2013, V. VII, No 7.

5. BISSO, Andrés, "El antifascismo latinoamericano...”, Op. Cit., p. 93.

6. PASOLINI, Ricardo, "Intelectuales antifascistas y...", Op. Cit. Por razones de extensión no ahondaremos sobre los estudios realizados por Pasolini con respecto a la sociabilidad antifascista, relevada a su vez en BISSO, Andrés, Sociedad política y movilización. Cuatro recorridos bonaerenses, Editorial Buenos Libros, Buenos Aires, 2009.

7. BISSO, Andrés, "El antifascismo latinoamericano...", Op. Cit. 
sobre el antifascismo de que este último se desarrolló principalmente durante la década de 1930 llama la atención, si se tiene en cuenta que ya desde la década anterior operaban en el país organizaciones fascistas fomentadas desde Italia para expandir el fascismo en la importante colectividad italiana argentina: los fasci italiani all'estero. Estas organizaciones fueron institucionalizadas desde el gobierno italiano en un proceso que se extendió -a grandes rasgos- entre 1923 y 1928, y que consistió en su subordinación a las autoridades consulares fascistizadas, alejándolas de cualquier tipo de acción política en el extranjero. El accionar de los fasci debía limitarse exclusivamente a los confines de las distintas colectividades italianas fuera de Italia, evitando cualquier vinculación con la política interna de los países receptores.

En el caso de América Latina, y de la Argentina en particular, João Bertonha afirma que desde Italia se llegaría a la conclusión de que el avanzado proceso de desnacionalización de las colonias solo podría ralentizarse, utilizándoselas a lo sumo como instrumentos de difusión de la ideología fascista en la opinión pública. ${ }^{8}$ Por su parte, De Caprariis sostiene que, en la Argentina, las oportunidades del fascismo eran muy poco prometedoras como consecuencia de la tradición democrática de la población italiana residente en el país, lo que dejó a los fascistas escaso espacio político para su organización. ${ }^{9}$

8. BERTONHA, João Fábio, "Emigrazione e política estera: la «diplomazia sovversiva» di Mussolini e la questione degli italiani all'estero, 1922-1945", en Altreitalie, Turín, 2001, № 23.

9. DE CAPRARIIS, Luca, "Fascism for export'? The Rise and Eclipse of the Fasci Italiani all'Estero", en Journal of Contemporary History, Londres, 2000, No 35, V. II, p. 158.Traducción del autor.
La mayoría de los estudios sobre el fascismo italiano en la Argentina se han enfocado también en la década de 1930, tanto por el impacto que tuvo en ella para motivar el desarrollo del antifascismo argentino ${ }^{10}$ como por el hecho de que fue en esa década cuando la red de fasci alcanzó su máximo desarrollo en el país. ${ }^{11}$ Con todo, no faltan relevamientos respecto al surgimiento de los fasci durante la década de 1920, aunque siempre subordinado al desarrollo principal de los mismos en los años ' $30 .{ }^{12}$

Otra posible interpretación de la mencionada limitación cronológica de los estudios puede ligarse a la caracterización que Bisso hace de la resistencia antifascista entre los italianos de la Argentina como sectarizada, lo que indica "la incapacidad y la falta de deseo de convertir al antifascismo en un ideal a compartir con el

10. PRISLEI, Leticia, "Redes intelectuales ante el fascismo: polémicas culturales y políticas acerca de las leyes raciales italianas y los exilios en Argentina", en Pasado y Memoria. Revista de Historia Contemporánea, Alicante, 2012, No 11, pp. 93-113.

11. Tanto en DEVOTO, Fernando, Historia de los italianos en la Argentina, Biblos, Buenos Aires, 2006, como en PRISLEI, Leticia, Los orígenes del fascismo argentino, Edhasa, Buenos Aires, 2008, se realizan menciones al accionar de los fasci y las filiales de la Opera Nazionale Dopolavoro, además de en la Ciudad de Buenos Aires, en las ciudades de Rosario, Santa Fe, La Plata, Junín, Bahía Blanca, Córdoba, Mendoza Tucumán, San Juan, Salta o Jujuy, entre otras localidades del interior del país.

12. DE CAPRARIIS, Luca, "Fascism for export'? ...", Op. Cit.; GRILLO, María Victoria, "Creer en Mussolini. La proyección exterior del fascismo italiano (Argentina, 1930-1939)", en Ayer, Valladolid, 2006, № 62, V. II, pp. 231-256; GONZÁLEZ CALLEJA, Eduardo, "De emigrantes a representantes de la nación en el extranjero: la política de encuadramiento partidista de los Fasci Italiani all'Estero", en Pasado y Memoria. Revista de Historia Contemporánea, Alicante, 2012, № 11. 
movimiento obrero local", ${ }^{13}$ hecho que ocasionó que el desarrollo del antifascismo argentino no se diera a partir de los antifascistas italianos en el país, sino en base a la utilización del ideal antifascista para hacer frente a los regímenes dictatoriales o fraudulentos locales.

Consideramos en este punto que las elecciones de enero de 1927 de la Sociedad Italia Unita permiten analizar que, si bien las primeras manifestaciones de la disputa fascismo-antifascismo se dieron dentro de los confines de la colectividad italiana al manifestarse en el seno de su principal entidad mutualista, esta involucró al CSBB, una organización política argentina, que hizo uso de la retórica antifascista para promover activamente la campaña de la lista opositora desde las páginas de su órgano de prensa.

Por último, es necesario tener en cuenta la importancia de las entidades mutuales en relación con el proceso inmigratorio italiano en la Argentina, temática que ha sido estudiada profusamente y que puede brindar nociones que posibiliten una mejor comprensión del caso que nos proponemos analizar. ${ }^{14}$ Nos interesa

13. BISSO, Andrés, "El antifascismo argentino...", Op. Cit., p. 212.

14. DEVOTO, Fernando, "La experiencia mutualista italiana en la Argentina: un balance”, en DEVOTO, Fernando y MÍGUEZ, Eduardo (compiladores) Asociacionismo, trabajo e identidad étnica. Los italianos en América Latina en una perspectiva comparada, CEMLACSER-IEHS, Buenos Aires, 1992, pp. 169-185; GANDOLFO, Romolo, "Las sociedades italianas de socorros mutuos de Buenos Aires: cuestiones de clase y etnia dentro de una comunidad de inmigrantes, (18801920)", en Ídem, pp. 311-332; DEVOTO, Fernando, "Participación y conflictos en las sociedades italianas de socorros mutuos”, en DEVOTO, Fernando y ROSOLI, Gianfausto (editores) La inmigración italiana en la Argentina, Biblos, Buenos Aires, 2000, pp. 141-164; DEVOTO, Fernando, Historia de los..., Op. Cit. sobre todo la caracterización que en tales trabajos se hace de las mismas y los datos que se ofrecen para mostrar su progresivo declive en el período que nos ocupa, ya que ambos elementos brindan claves interpretativas de utilidad para nuestro análisis. En primer lugar, Devoto resalta la prohibición, en todas las entidades, de la actividad política, hecho que llevaba a la denuncia de la práctica política en tanto se la veía de manera negativa..$^{15}$ Esto no lleva al autor a negar la existencia de conflictos en el seno de las entidades, sino a afirmar que no se vinculaban con la sociedad receptora sino con la sociedad de origen. A su vez, también ha observado que, en gran medida, la conflictividad interna de las entidades respondía más a conflictos personales que a motivaciones ideológicas o regionalismos. ${ }^{16}$

Por otro lado, en cuanto al progresivo declive que siguió, hacia la década de 1920, al auge de las entidades mutuales italianas, Devoto señala las crecientes dificultades que atravesaron para mantener el espíritu de nacionalidad entre los italianos en la Argentina, tanto por la reducción en el flujo inmigratorio como por la creciente argentinización de los hijos de italianos. Este hecho reviste una particular importancia si se tiene en cuenta que era una preocupación del gobierno de Mussolini retardar, a través de la promoción de la italianidad entre los inmigrantes, ese proceso de desnacionalización, tarea en la cual las instituciones que procedían de la época liberal constituían un instrumento clave. Es por esto que tales instituciones (mutualistas, educativas, recreativas, entre otras) fueron un blanco de la

15. DEVOTO, Fernando, Participación y conflictos..., Op. Cit., p. 161.

16. DEVOTO, Fernando, Historia de los..., Op. Cit., p. 173. 
política fascista en el exterior, buscándose su control a través de la cooptación y existiendo también la posibilidad de la creación de nuevas entidades (como los fasci o los dopolavori).

Estos dos elementos permiten echar luz sobre el caso de la Sociedad Italia Unita, en tanto posibilitan, por un lado, analizar el tipo de conflicto entablado entre las listas rivales $y$, por el otro, comprender la importancia del control de la institución en el contexto descripto. Si se considera el conflicto en clave ideológica, el hecho de que desde Italia se pretendiera difundir en la colectividad local una italianidad fascistizada, que incluyera al fascismo como otra página gloriosa de la nación, hizo que la lucha por el control de la institución pudiera ser percibida desde el antifascismo como una batalla para evitar que desde el gobierno de Italia se avanzase en la fascistización de la colonia italiana de Bahía Blanca. Por otro lado, si se tiene en cuenta la afirmación de Devoto de que el peso de las rivalidades ideológicas era mucho menor que el de las rivalidades personales (idea que coincide con la que sostiene Bisso, referida más arriba), podríamos entender que en el conflicto tuviera lugar además un intento, por parte de un grupo de individuos que nunca habían tomado parte en la dirección de la entidad, de desplazar de los cargos directivos a personas que desde hacía quince años se hallaban al frente de la institución, con la carga de prestigio que ello conllevaba dentro y fuera de la colectividad.

\section{Breve introducción al caso de Bahía Blanca}

Antes de analizar los actores e instituciones que tomaron parte en el caso que estudiamos, consideramos necesario hacer mención de la importancia del flujo inmigratorio en la conformación demográfica y socioeconómica de Bahía Blanca entre fines del siglo XIX y principios del XX. La bibliografía al respecto es abundante y en ella se destaca el rol de la inmigración italiana en la ciudad, presente en el medio bahiense a través de diversas asociaciones recreativas y mutualistas entre las que se encuentra la que analizamos. ${ }^{17}$

En 1912 se constituyó la Sociedad Italiana de Socorros Mutuos e Instrucción Italia Unita, como resultado de la fusión de las tres entidades peninsulares más importantes de Bahía Blanca, englobando funciones que iban desde la vinculación social de los inmigrantes hasta la asistencia sanitaria, pasando por la organización de las escuelas italianas de la ciudad. ${ }^{18}$

La constitución de la Sociedad fue resultado de una Asamblea General Extraordinaria realizada el 23 de diciembre de 1911, en la cual se decidió la fusión de la Sociedad Italiana de Socorros Mutuos (fundada el 2 de abril de 1882), la Sociedad Italiana de Socorros Mutuos e Instrucción XX de Septiembre (fundada el 14 de septiembre de 1886), y la Sociedad Italiana Meridional de Socorros

17. Ver, por ejemplo, MONACCI, Gustavo, "Inmigración" en WEINBERG, Félix (director) Historia del sudoeste bonaerense, Plus Ultra, Buenos Aires, 1988, pp. 205-243; CERNADAS, Mabel, "Inmigración y vida cotidiana en Bahía Blanca hacia 1880", en WEINBERG (director) Estudios sobre inmigración II, Universidad Nacional del Sur, Bahía Blanca, 1994, pp. 5-77; BUFFA, Norma, "Inmigración y movimiento obrero en Bahía Blanca durante la primera década del siglo XX. Sus ideologías”, en Ídem, pp. 79-110.

18. MONACCI, Gustavo, “Inmigración”..., Op. Cit., p. 214. 
Mutuos (fundada el 29 de enero de 1906). ${ }^{19}$ La constitución definitiva de la Sociedad Italia Unita se efectivizó el 4 de marzo de 1912, y el 7 de mayo se realizaron las elecciones generales que establecieron la primera Comisión Directiva, encabezada por el presidente Luis Godio y el vicepresidente Luis Salvadori. Estos dos nombres (así como muchos otros de las sucesivas Comisiones Directivas) aparecerían, años más tarde, vinculados al fascio "Giulio Giordani”, por lo que es interesante tener en cuenta que los fascistas locales no ingresaron a la vida pública de la colectividad italiana de la mano del fascismo, sino que contaban ya con una larga trayectoria en la misma. ${ }^{20}$

Nos interesa remarcar la recurrencia de los nombres ligados al fascio durante los primeros quince años de vida de la Sociedad Italia Unita, tiempo que en una parte importante transcurrió antes de la propia existencia del fascismo. Consideramos que es un aspecto relevante teniendo en cuenta la politización de las elecciones de enero de 1927. En efecto, desde la lista ligada al CSBB se plantearía abiertamente el carácter político de los comicios, que chocaba con la concepción de la entidad como una organización social apolítica de una colectividad inmigratoria. Si tenemos en cuenta que en la lista calificada de fascista

19. CROCITTO, Geremia et al., Un siglo de vida de la Sociedad Italiana de Socorros Mutuos de Bahia Blanca, Palumbo Hnos., Bahía Blanca, 1982, p. 48.

20. Entre 1912, año de la fundación, y 1926, año de la constitución del fascio “Giulio Giordani”, pasaron por las sucesivas Comisiones Directivas varias personalidades que tendrían una participación activa en el fascismo local. Entre ellos, además de Godio y Salvadori, se cuenta a Pilade Maffi (varias veces presidente), Ubaldo Monacelli, Juan Iscardi (también aparece como Isoardi en la prensa), Ciro Arena, Félix Cantarelli, Humberto Oliva, Septimio Facchinetti, Pablo Zichella, Ricardo Gerardi y Juan Antonio Canessa.

124 se inscribían nombres de larga trayectoria en la dirección de la Sociedad Italia Unita, podemos suponer que fue la novedosa presencia del fascio "Giulio Giordani" en la ciudad lo que generó la percepción de que la contienda electoral de 1927 no era como las anteriores.

E1 fascio "Giulio Giordani", la primera institución fascista en la ciudad, fue fundado el 15 de mayo de 1926 en una asamblea realizada en la sede del viceconsulado de Italia, a la que asistieron, entre los más de cien concurrentes, distinguidos miembros de la colectividad italiana, apareciendo en el directorio varios apellidos reconocidos. ${ }^{21} \mathrm{El}$ accionar del fascio estaría guiado por los objetivos que desde Roma se impartían a todos los fasci fuera de Italia: mantener una conducta ejemplar, respetar las leyes de los países en que se asentaban y no inmiscuirse en su política interna, y difundir propaganda sobre los logros económicos, sociales y culturales de Italia, buscando así la fascistización de los connacionales. En consonancia, los miembros del fascio bahiense desarrollaron principalmente actividades sociales y culturales (festivales, banquetes, conferencias, ceremonias, etc.) dentro de los confines de la colectividad italiana local. ${ }^{22}$ En este punto, es crucial destacar la estrecha relación entre el fascio y el viceconsulado de Italia, siendo el vicecónsul Giorgio Foresti, arribado a la ciudad el 27 de febrero de 1926,

21. Ver El Atlántico, Bahía Blanca, 21/05/1926, p. 3.

22. Para un análisis más extenso de los comienzos del fascio, así como de las actividades por este realizadas y los vínculos tendidos con otras instituciones y personalidades de la ciudad, ver CIMATTI, Bruno, "De la 'gavilla fascista' a la Casa del Italiano. Los primeros pasos del fascismo en Bahía Blanca (1926-1927)”, ponencia presentada en XV Jornadas Interescuelas/Departamentos de Historia, Universidad Nacional de la Patagonia San Juan Bosco, Comodoro Rivadavia, 2015. 
uno de los principales promotores y miembro reconocido de la institución fascista bahiense. Esta vinculación sería vista con alarma desde el antifascismo local, ya que garantizaba a los fascistas locales el apoyo constante de la legación diplomática italiana.

Sin embargo, lo que nos interesa principalmente es la búsqueda por parte del fascismo del control de las instituciones surgidas durante la etapa de la Italia liberal. En este marco cobra un papel simbólico muy importante la presencia del fascio en la ciudad para las elecciones de enero de 1927. $\mathrm{Si}$ pensamos que durante los quince años precedentes habían ocupado importantes puestos en la sociedad muchos individuos que en la elección de 1927 conformaron la lista oficialista (lo que significa que muchos ya ocupaban cargos ganados en la elección anterior), podemos apreciar que la concepción de los comicios como una disputa política entre fascismo y antifascismo por el control de la Sociedad Italia Unita fue resultado de la activa presencia que el fascio "Giulio Giordani" tenía desde hacía meses en la ciudad. Como veremos, esta politización de las elecciones se reflejó principalmente en las páginas de Nuevos Tiempos, órgano de prensa del CSBB.

Para finalizar este acercamiento a la etapa que nos ocupa resulta necesario realizar un breve esbozo de la historia del socialismo local, ya que fue desde el CSBB que se articuló la lista opositora en las elecciones de la Sociedad Italia Unita. ${ }^{23} \mathrm{La}$ institucionalización del

23. Para un análisis en mayor profundidad ver CIMATTI, Roberto, "Concejales, trabajadores y militantes sindicales. Algunas observaciones sobre el núcleo dirigente del socialismo bahiense (19161930)", en DEL VALLE, Laura y EBERLE, Adriana (compiladoras) Pensar e investigar el poder, Ediuns, Bahía socialismo en la ciudad se produjo en 1894 con la constitución del Centro Unión Obrera, conformado en gran parte por italianos, que más tarde se ampliaría a otras nacionalidades y en 1897 se reconstituiría como Centro Socialista Obrero de Bahía Blanca, integrado al Partido Socialista Obrero Argentino. En 1907, tras una crisis partidaria que finalizó con la escisión de sectores vinculados al sindicalismo revolucionario, el CSBB se reorganizó y comenzó a consolidarse en la ciudad avanzando en el desarrollo de su actividad en sindicatos y cooperativas, así como accediendo a bancas en el Concejo Deliberante o en la Legislatura bonaerense. Asimismo, a partir de 1913 comenzó a publicarse el órgano oficial de la institución, Lucha de Clases, posteriormente rebautizado Nuevos Tiempos. En junio de 1926, se promovió la constitución del Centro Antifascista "Giacomo Matteoti", abierto a todos los inmigrantes italianos sin diferenciaciones internas por tendencias políticas entre las distintas vertientes del antifascismo, cuyo principal objetivo era la "oposición neta contra el actual gobierno de Italia de tendencia fascista y de opresión [así como] contra toda dictadura y contra los que la defienden y tratan de solidarizarse con las corrientes reaccionarias y políticas en esta República”. ${ }^{24}$ En octubre del mismo año se constituiría el Frente Único Antifascista, con la adhesión de veintidós entidades obreras, culturales y políticas de la ciudad, para "contrarrestar la propaganda y actividad de los reaccionarios de todo pelaje que se escudan en la causa del Duce." 25

Puede afirmarse entonces que, hacia 1927,

Blanca, 2014, pp. 90-92.

24. Nuevos Tiempos, Bahía Blanca, 23/08/1926, p. 2.

25. Nuevos Tiempos, Bahía Blanca, 20/10/1926, p. 1. 
el CSBB constituía una organización política consolidada en la ciudad, con una variada ramificación de sus actividades políticas, sociales y culturales, y que representaba la tercera fuerza política bahiense, detrás de radicales y conservadores. ${ }^{26} \mathrm{~A}$ su vez, adquiere importancia el vínculo sostenido en tre el CSBB y la inmigración italiana, visible ya desde sus orígenes, si tenemos en cuenta que gran parte de los afiliados del partido eran trabajadores de esa procedencia. En este sentido, es importante tener en cuenta que ninguna de las Comisiones Directivas de la Sociedad Italia Unita había estado conformada por italianos o hijos de italianos ligados al CSBB. Por lo mismo, desde el socialismo bahiense se mostró interés por obtener la victoria en las elecciones generales de la Sociedad en 1927, bajo la percepción de que en ellas se libraba un combate decisivo contra el fascismo por el control de la institución y de las actividades por ella realizadas.

Esta imagen de un partido político local vinculado a la idea de la lucha antifascista permite complejizar la idea arriba mencionada de que hasta mediados de la década de 1930 el antifascismo se había limitado a los confines de la colectividad italiana, lo que puede vincularse con la apreciación de los fascistas locales como amenaza, así como con una utilización del conflicto italiano con fines electorales. En otras palabras, en tiempos previos a la internacionalización del conflicto entre fascismo y antifascismo puede apreciarse, en el caso bahiense, el involucramiento del CSBB, una organización política argentina, en unas elecciones que fueron interpretadas en clave antifascista.

26. CIMATTI, Roberto, "Concejales, trabajadores y militantes sindicales...”, Op. Cit., p. 100.

126
Encontramos también la que podría ser otra particularidad del caso analizado en relación con la presencia en la dirección de la Sociedad Italia Unita, durante toda su historia previa, de individuos que más tarde fueron miembros del fascio "Giulio Giordani". Esto llama la atención si se tienen en cuenta las afirmaciones que, en estudios específicos sobre las asociaciones mutuales, se hace respecto de sus dirigencias, caracterizadas por su pertenencia al ideal mazziniano y al republicanismo liberal italiano de la segunda mitad del siglo XIX. El propio Devoto observa que esta matriz republicana representó un obstáculo para la penetración del fascismo en tales instituciones. ${ }^{27} \mathrm{En}$ el caso estudiado vemos cómo la situación se da a la inversa, en tanto la histórica élite dirigente de la entidad estaba vinculada al fascio local y fueron los antifascistas quienes debieron disputar el control de la institución. Podemos hipotetizar que, en el caso bahiense, la élite dirigente de la colectividad italiana adoptaría una posición más pragmática que ideológica, intentando mantener su posición de prestigio. En este sentido, la vinculación al fascismo podría ser vista en función de las ventajas que esta ofrecería de allí en adelante (vínculos con el consulado y otros representantes del gobierno italiano que visitaran la ciudad, en términos de influencia social o de apoyo económico). Para la contrastación futura de esta hipótesis serán de utilidad los estudios existentes focalizados en otras localidades del país.

Podemos proceder ahora al análisis de las elecciones de enero de 1927. En primer lugar, prestaremos especial atención al clima previo a la realización de los comicios en las páginas de la prensa comercial de Bahía

27. DEVOTO, Fernando, Historia de los..., Op. Cit., p. 348. 
Blanca, la cual reflejó las campañas realizadas por ambas listas contendientes. En segundo lugar, consideraremos las consecuencias que el resultado de la elección tuvo tanto para la Sociedad Italia Unita como para los miembros $\mathrm{y}$ organizadores de ambas listas.

\section{Camino a las elecciones generales}

E1 26 de diciembre de 1926 se hizo pública, desde la Comisión Directiva de la Sociedad, la convocatoria dirigida a los socios para realización de la Asamblea que, el 16 de enero de 1927, procedería a la elección de presidente, vicepresidente, secretario, vicesecretario, tesorero, dieciocho consejeros, nueve miembros del Jurado de Honor, y tres síndicos. ${ }^{28}$

E1 8 de enero de 1927 se presentó en la prensa diaria la lista oficialista para las elecciones del día 16, conformada por "hombres representativos de la colectividad y antiguos socios de larga actuación", ${ }^{29}$ la cual buscaba expresar "los anhelos del grupo que la representa, inspirado en la armonía de la colectividad italiana." ${ }^{30}$ La lista estaba encabezada por Pilade Maffi, aspirante a la reelección como presidente $\mathrm{y}$ miembro del Comité Ejecutivo de Propaganda fascista en la ciudad. ${ }^{31}$ Acompañaban a Maffi muchos miembros del fascio, entre ellos Juan Iscardi como candidato a vicepresidente, Domingo Lamonea como candidato a síndico,

28. Ver La Nueva Provincia, Bahía Blanca, 27/12/1926, p. 15.

29. El Atlántico, Bahía Blanca, 08/01/1927, p. 7.

30. Ibídem.

31. Ver La Nueva Provincia, Bahía Blanca, 22/12/1926, p. 11. y Luis Godio, Juan Antonio Canessa, Alberto Rabino y Adolfo Robotti como candidatos a miembros del Jurado de Honor.

Al mismo tiempo, desde Nuevos Tiempos se anunciaba la formación de un proyecto "encaminado a sacar de las garras del cónsul fascista y sus sirvientes, la dirección y administración de su principal entidad mutualista". ${ }^{32}$ Esto evidencia que, desde el socialismo, se consideraban las elecciones como la oportunidad de evitar que la entidad cayera en manos del fascismo, representado en el vicecónsul Foresti, que había arribado a la ciudad casi un año antes. ${ }^{33}$ En este sentido, consideramos que el impacto de la constitución del fascio, en el mes de mayo, así como el rol activo de Foresti en la misma, permitió la concepción de los comicios como una contienda en términos de fascismoantifascismo.

E19 de enero se dio a conocer la constitución de una lista opositora denominada "Italia Libera”. Desde las páginas de Nuevos Tiempos se llamaría a votar a la nueva fórmula, encabezada por Marzio Cantarelli: "votar por esa lista significa librar a la Sociedad de las manos de los fascistas locales que creen disponer a su antojo de los bienes sociales". ${ }^{34}$ En la lista acompañaban a Cantarelli varios individuos de importancia en el CSBB, tales como Francisco Lódolo, candidato a consejero, antiguo afiliado de importante trayectoria y uno de los primeros tres concejales del socialismo en la ciudad, Celestino Luchetti por el cargo de secretario y Juan Cittá como

32. Nuevos Tiempos, Bahía Blanca, 12/01/1927, p. 3.

33. Arte y Trabajo, Bahía Blanca, 31/07/1926, p. 8.

34. Nuevos Tiempos, Bahía Blanca, 15/01/1927, p. 1. 
postulante a síndico de la entidad. ${ }^{35}$

Con todo, la campaña no consistió únicamente en las calificaciones políticas efectuadas desde el bisemanario socialista, sino que ambas listas tenían sus propuestas vinculadas con la gestión de la Sociedad Italia Unita. La lista oficialista contaba a su favor con los resultados obtenidos durante su gestión, que dejaba "la Administración con un beneficio líquido que pasa de 15.000 pesos moneda nacional, lo que habla elocuentemente de la eficacia y patriotismo con que respondió al voto de los socios que consagró la lista el año anterior". ${ }^{36}$ Además de la buena posición económica, se publicitaba la gestión satisfactoria e imparcial de los servicios sociales, "pues se ha entendido que la obra de la sociedad es para todos, sin distingos de ninguna clase" ${ }^{37} \mathrm{La}$ principal propuesta de la lista oficialista era la construcción de un nuevo edificio para albergar a la Sociedad, del que Maffi, en una entrevista brindada a El Atlántico en la que además remarcó la necesidad de que "no se malogre el éxito alcanzado en la administración que realizamos en 1926", ${ }^{38}$ dijo: "procuraremos que la obra sea digna de la importancia de Bahía Blanca y lo inauguraremos como uno de los números de los festejos del centenario de la ciudad". ${ }^{39}$

Mientras la campaña de la lista oficialista se basaba, fundamentalmente, en los resultados obtenidos durante la gestión previa, desde

35. CIMATTI, Roberto, "Concejales, trabajadores y militantes sindicales...”, Op. Cit., p. 94.

36. La Nueva Provincia, Bahía Blanca, 08/01/1927, p. 9.

37. La Nueva Provincia, Bahía Blanca, 16/01/1927, p. 7.

38. Ibídem.

39. El Atlántico, Bahía Blanca, 16/01/1927, p. 5.

128
"Italia Libera" se presentaba una vocación de renovar la institución, "tratando de llevar adelante diversas iniciativas que por su amplitud, por su carácter y por lo que requieren de actividad para su desarrollo, desde luego que no es bastante todo un período de labor". ${ }^{40}$ Desde la nueva lista se buscaba crear una caja de seguros mutuos, así como una oficina de trabajo para orientar a los inmigrantes recién llegados a la ciudad, reformar los servicios médicos y farmacéuticos, restablecer la laicidad en las escuelas dependientes y extender la educación gratuita a los adultos. A su vez, también incluían en sus planes la construcción de una nueva sede para la entidad y buscaban constituir cooperativas de producción, trabajo y consumo. ${ }^{41}$ En una entrevista brindada a El Atlántico, el candidato a presidente por "Italia Libera" no hizo mención alguna al fascismo en la ciudad sino que acotó sus palabras únicamente a cuestiones propias de la institución (posiblemente por el carácter apolítico de la misma), enfatizando varias de las propuestas mencionadas y criticando una de las banderas que enarbolaba la lista rival: el superávit financiero. El candidato veía como "un error que una sociedad mutualista aspire a acumular dinero haciendo economías en medicinas y asistencia médica para los socios necesitados". ${ }^{42}$ A su vez, se realizaron distintos actos de propaganda en barrios obreros, en los que se explicaría "a los socios e italianos concurrentes el programa de labor que sostendrá la lista denominada antifascista". ${ }^{43}$ Consideramos relevante el hecho de que, mientras en las declaraciones a la prensa

40. La Nueva Provincia, Bahía Blanca, 16/01/1927, p. 7.

41. Ibídem.

42. El Atlántico, Bahía Blanca, 16/01/1927, p. 5.

43. Nuevos Tiempos, Bahía Blanca, 12/01/1927, p. 1. 
diaria de la ciudad no aparece mención a la lucha antifascista, esta formaba parte de la propaganda realizada en distintos barrios obreros de la misma y se reflejaba en el órgano de prensa del CSBB.

E1 16 de enero se realizaron las elecciones generales de la Sociedad Italia Unita. A ella se presentaron dos bandos cuyas propuestas fueron difundidas en las principales publicaciones de prensa de la ciudad. Sus programas, según La Nueva Provincia (que en todo momento mostró su preferencia por la lista oficialista), se caracterizaban "el uno por una acción eficiente ya desarrollada $\mathrm{y}$ que no se puede discutir en su alto valor y en sus beneficios positivos para los asociados y para el progreso de la entidad y el otro por el entusiasmo y la buena voluntad de sus autores que luchan puede decirse, desde el llano". ${ }^{44}$ Sin embargo, el mismo diario estableció que en la contienda electoral a realizarse ese día "más se actúa por cuestiones ideológicas que por otra causa”. ${ }^{45}$

E1 acto eleccionario despertaría "el más vivo interés entre los afiliados a la entidad", ${ }^{46}$ llegando a sostenerse que fue "la primera vez desde que la sociedad Italia Unita existe, que se haya despertado tan intenso interés". ${ }^{47}$ Esto puede comprenderse si tenemos en cuenta que para muchos de los votantes la elección no era entre Maffi y Cantarelli, o entre la lista oficialista e "Italia Libera", sino que constituía la manifestación local de la disputa entre fascismo y antifascismo.

44. La Nueva Provincia, Bahía Blanca, 16/01/1927, p. 7.

45. Ibídem.

46. Ibídem.

47. El Atlántico, Bahía Blanca, 18/01/1927, p. 5.

\section{Las elecciones generales de la Sociedad Italia Unita}

Los comicios se desarrollaron con normalidad entre las 10 y las 17 horas del 16 de enero de 1927. Concurrieron a votar más de 800 socios (sobre un total de 1986 a fines de 1926), ${ }^{48}$ hecho que llevaría a El Atlántico a afirmar que "pocas veces una elección de comisión directiva en una institución mutualista despertó tanto interés".$^{49} \mathrm{El}$ resultado sería una victoria de la lista "Italia Libera" por 476 votos contra 340 en la elección de la Comisión Directiva, 481 sobre 328 en la lista de síndicos, y 486 contra 333 en la lista del Jurado de Honor. Se realizaba así un cambio en la totalidad de los miembros de la dirigencia de la Sociedad, cosa que no sucedía a grandes rasgos desde su fundación y que llevaba al poder a candidatos que, en palabras de La Nueva Provincia, eran apoyados por "el elemento joven renovador, de tendencia ideológica determinada que se ha propuesto llevar un nuevo ambiente, una nueva acción, una nueva orientación de democracia a la sociedad". ${ }^{50}$ Según El Atlántico ese cambio fue muy bien recibido en el seno de la Sociedad italiana por el reconocimiento de Cantarelli como "hombre emprendedor y progresista, que ha de desarrollar una labor muy interesante al frente de la poderosa institución mutualista". ${ }^{51}$

Sin embargo, el cambio de Comisión Directiva significó mucho más si se lo analiza desde sus implicancias políticas, que

48 CROCITTO, Geremia et al., Un siglo de vida..., Op.

Cit., p. 72.

49 Ibídem.

50 La Nueva Provincia, Bahía Blanca, 17/01/1927, p. 4.

51 El Atlántico, Bahía Blanca, 18/01/1927, p. 5. 
no aparecen reflejadas en la prensa diaria de la ciudad. En efecto, para Nuevos Tiempos el resultado significaba el triunfo de "los hombres de ideas liberales y democráticas de la entidad mutualista, que han luchado y conseguido sustraerla del dominio del cónsul mussolinístico y sus fieles y obsecuentes lacayos". ${ }^{52}$ A su vez, se buscaba remarcar la estrategia de los miembros del fascio que había sido desbaratada por el accionar antifascista, describiendo a la lista perdedora como "una lista compuesta de capitalistas incoloros, algunos elementos independientes y mezclados a ellos, tres o cuatro militantes del 'piccolo' fascio local', creada al efecto de desorientar a los votantes para obtener votos que no hubieran conseguido de presentar una lista expresamente fascista. ${ }^{53}$

El resultado de las elecciones significó, como dijimos, más que un cambio en la composición de la Comisión Directiva. La derrota infligida a la lista encabezada por Maffi fue vista, desde el antifascismo local, como una victoria definitiva sobre los fascistas bahienses. Tanto es así que se dijo del vicecónsul Foresti que "ante el fracaso del domingo, si tiene un poco de amor propio, debe renunciar y ausentarse al lado de su patrón, pues aquí no es campo propicio para sus ideas dictatoriales". ${ }^{54}$

Ambas listas se reunirían la noche de los comicios. En los festejos realizados por la lista "Italia Libera" realizarían intervenciones varios dirigentes socialistas entre los que se destacó Agustín de Arrieta. Por su parte, la lista derrotada se reunió en el Hotel d'Italia (administrado por Luis Godio, presidente

52. Nuevos Tiempos, Bahía Blanca, 19/01/1927, p. 1.

53. Ibídem.

54. Ibídem. honorario del fascio "Giulio Giordani" en tiempos de su fundación), lugar en el que realizaron una cena de camaradería para intercambiar opiniones "acerca de la acción futura a desarrollar en favor de la armonía de la colectividad italiana". ${ }^{55}$

Las actividades públicas del fascio serían escasas en los meses subsiguientes, y recién en octubre se inauguraría la Casa del Italiano, una institución cultural en apariencia apolítica que buscaba reunir en torno de sí a la colectividad entera. En efecto, harían uso de la idea de armonía entre los italianos de la ciudad, para contrarrestar una supuesta politización del sector antifascista. Esto se puede apreciar en el debate por la participación de la colectividad en los festejos del centenario de la ciudad, que tendría su resolución en mayo de $1927 .{ }^{56}$

E1 25 de ese mes se anunciaba el inicio de los preparativos iniciados por "un núcleo calificado de la colectividad italiana" ${ }^{\text {7 }}$ para los festejos del centésimo aniversario de la fundación de Bahía Blanca, "previo intercambio de ideas con el R. Cónsul de Italia en Bahía Blanca, Dr. J. Foresti". ${ }^{8}$ Se publicitaba una asamblea a realizarse el 29 en un bar de la ciudad, a la cual se convocaba a todos los italianos interesados, finalizando con la inscripción de la nómina de individuos que conformaban dicho núcleo, entre los cuales se encontraban

55. El Atlántico, Bahía Blanca, 18/01/1927, p. 5.

56. Este conflicto ha sido relevado en VECCHI, Rodrigo, "De escuadras, compases y camisas negras: el monumento a Giuseppe Garibaldi o la representación formal de los conflictos en la colectividad italiana bahiense (1927-1928)", en Discutir el canon. Tradiciones y valores en crisis, CAIA, Buenos Aires, 2003, pp. 598-599.

57. La Nueva Provincia, Bahía Blanca, 25/05/1927, p. 11.

58. Ibídem. 
varios miembros reconocidos del fascio y otros personajes ligados al mismo. Inmediatamente, desde la dirección de la entidad italiana se expidió una convocatoria a una asamblea paralela, a realizarse también el 29 de mayo en la sede de la Sociedad, "tendiente a considerar diversos detalles atingentes con el propósito que auspicia la sociedad Italia Unita, de tributar a nuestra ciudad un homenaje en su próximo centenario". ${ }^{59}$

El resultado de ambas asambleas fue la constitución de dos comisiones guiadas por el mismo objetivo de organizar el plan de acción para la participación italiana en las celebraciones del centenario. Por un lado se encontraba la comisión cuyo presidente honorario era Foresti, en cuya asamblea se expresó el deseo de "obtener la fusión con aquellas otras comisiones de la colectividad que puedan constituirse con el mismo objeto, a fin de aunar fuerzas y medios de recurso". ${ }^{60}$ Por su parte, en la reunión celebrada en las dependencias de la Sociedad Italia Unita se procedió al nombramiento de la Comisión Pro Homenaje a la Ciudad de Bahía Blanca, conformada por los directivos de las sociedades italianas de Bahía Blanca y localidades aledañas.

Frente a esta división, aparecería en La Nueva Provincia una nota, firmada por Luis Godio y Alberto Rabino, vinculados al fascio, en la que se lamentaban de que su deseo de que el recuerdo de la fundación de la ciudad fuese "algo sagrado en todo corazón italiano y que su Centenario haría olvidar toda rencilla, toda lucha política y juntos se encontraran en una sola armonía", ${ }^{61}$

59. La Nueva Provincia, Bahía Blanca, 29/05/1927, p. 6. 60. La Nueva Provincia, Bahía Blanca, 31/05/1927, p. 14. 61. Ibídem. se hubiera visto "momentáneamente desbaratado por la inconsulta precipitación de un bando y la tergiversación de los hechos del otro". ${ }^{62}$ Vemos cómo los miembros del fascio buscaban presentarse como defensores de la unión de todos los italianos frente a un sector que interpretaba sus actitudes como acciones de mala fe, al ver el llamado a una asamblea no oficial como un desconocimiento de la entidad, tendiente a confundir a los italianos en beneficio propio. ${ }^{63}$

Finalmente, el carácter oficial que tuvo la Comisión Pro Homenaje, auspiciada desde la Sociedad Italia Unita, hizo que el proyecto presidido de modo honorario por Foresti no prosperara. En una asamblea celebrada el 30 de junio se resolvió que la colectividad italiana participaría de las celebraciones del centenario mediante el emplazamiento, en una de las plazoletas del Teatro Municipal, de un monumento a Giuseppe Garibaldi. ${ }^{64}$

El caso reseñado nos permite apreciar otra de las consecuencias fundamentales que tuvo el resultado de las elecciones realizadas en enero, esto es, el distanciamiento entre la Sociedad Italia Unita y el viceconsulado de Italia en Bahía Blanca. A este respecto, Crocitto sostiene que hasta el año 1926 la colectividad italiana era "indiferente al movimiento creado por Mussolini”, manteniéndose a grandes rasgos unida. ${ }^{65}$ Posteriormente, sostiene que a inicios de 1927 pasaron a conformar la Comisión Directiva "varios socios de neto

62. Ibídem.

63. Ver Nuevos Tiempos, Bahía Blanca, 28/05/1927, p. 3.

64. Ver La Nueva Provincia, Bahía Blanca, 03/07/1927, p. 8 .

65. CROCITTO, Geremia et al., Un siglo de vida..., Op. Cit., pp. 60-61. 
corte antifascista" ${ }^{66} \mathrm{Si}$ bien puede cuestionarse la supuesta indiferencia de la dirección de la Sociedad hacia el fascismo hasta 1926, es de interés la referencia que hace el autor al conflicto desatado entre la entidad mutual italiana y el viceconsulado de Italia en Bahía Blanca tras la asunción de la nueva dirigencia de la primera: el 11 de marzo de 1927 la Comisión Directiva realizó una reprobación pública al vicecónsul por su condición de fascista, situación de la que más tarde se derivaría la conformación de comisiones separadas para la organización de los festejos del centenario, con el desenlace arriba mencionado y la cancelación de los depósitos y la cuenta corriente de la entidad en el Banco de Italia y Río de la Plata. ${ }^{67}$ En adelante, y hasta 1931, la Sociedad y el viceconsulado transitarían por sendas separadas, sin participar conjuntamente en la conmemoración de ninguna fecha patria italiana. Finalmente, el 26 de septiembre de 1931, el Presidente de la Sociedad Marzio Cantarelli, en ese cargo desde 1927, y el regente del viceconsulado Coronel Cesare Afeltra, reanudaron las relaciones bajo el lema "Unión y Concordia entre los Italianos". ${ }^{68}$

\section{Algunas conclusiones preliminares}

La reanudación de las relaciones, así como el acceso en 1933 a la Comisión Directiva (y su permanencia en los cargos en años sucesivos) de un nuevo conjunto de individuos que se mostrarían cercanos al fascismo, cierran la etapa abierta por las elecciones de la Sociedad

66. Ídem, p. 61.

67. Ídem, p. 69.

68. Ídem, p. 70.

132
Italia Unita de enero de 1927. Consideramos que ese período tiene especial importancia para analizar qué modalidades tomó la lucha entre fascistas y antifascistas en el seno de las instituciones italianas, y, particularmente, en la Sociedad Italia Unita de Bahía Blanca. Hemos podido apreciar cómo esa lucha, librada en el seno de una entidad que desde sus orígenes se pretendió apolítica, adquirió alternadamente los tintes de una disputa de carácter ideológicopolítico y un cariz de tipo administrativo. En virtud de esta segunda faceta, no debe olvidarse que controlar la Sociedad no solo constituía una posición de prestigio y de gran proyección pública en la sociedad bahiense, sino que además significaba la administración del gran capital económico de la institución.

En este punto consideramos relevante la interpretación realizada por Bisso de un antifascismo despojado de su concepción épica, y entendido como instrumento político para perseguir fines locales concretos. ${ }^{69}$ Desde esta óptica, puede interpretarse que la lista opositora, valiéndose del prestigio de la etiqueta "antifascista", logró ocupar la dirección de la entidad, desplazando a individuos que se encontraban en el poder desde la fundación de la misma. Si bien es innegable la vinculación de estos hombres con el fascismo, esta interpretación posibilita tener en cuenta las relaciones y rivalidades interpersonales entre individuos destacados de la colectividad italiana, que hallarían en la disputa fascismo-antifascismo justificaciones de alcance universal para su pugna por intereses concretos.

Las elecciones de 1927 constituyeron la

69. BISSO, Andrés, "El antifascismo latinoamericano...", Op. Cit. 
materialización de esa contienda en la entidad mutual italiana, en tanto posibilitaron el acceso a la Comisión Directiva de distinguidos miembros del antifascismo local, que desde sus puestos se enfrentarían al viceconsulado, correa de transmisión de las directivas impartidas desde Roma. Esa disputa se desarrollaría en los años subsiguientes, y durante la década de 1930 la gravitación del fascismo en la colectividad italiana de la ciudad sería mucho mayor, a través de la creación de diversas instituciones como el dopolavoro "Ugo Quintavalle”, el Instituto Ítalo Argentino de Cultura "Umberto di Savoia" (organizado para englobar a las escuelas italianas que existían en la ciudad) o la organización juvenil "Giovani Italiani all'Estero".

Creemos que el análisis de casos como el que estudiamos es importante para la reconstrucción de la historia y el accionar del fascismo y del antifascismo en la ciudad, ya que permite entender las estrategias y actividades llevadas adelante por sus miembros. Esperamos, por lo mismo, que este artículo sea un aporte de utilidad para entender los distintos modos en que la disputa entre fascismo y antifascismo se manifestó en las instituciones italianas de la Argentina.

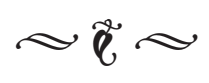

Recibido: 04 - 04 - 2016

Aceptado: 13 - 06 - 2016

Publicado: 30 - 06 - 2016 


\section{Bibliografía}

ALDRIGHI, Clara, Antifascismo italiano en Montevideo: El diálogo político entre Luigi Fabbri y Carlo Rosselli, Universidad de la República, Montevideo, 1996.

ARDANAZ, Eleonora, "Pelando papas se combate al fascismo: roles y funciones de las asociaciones antifascistas de Bahía Blanca durante la Guerra Civil Española”, en Cuadernos de H Ideas, La Plata, 2013, V. VII, No 7, pp. 1-17. Disponible en: <http://perio.unlp.edu.ar/ojs/index.php/cps/article/ view/2055/1800> [Consulta: 5 de junio de 2016].

BERTONHA, João Fábio, Sob a sombra de Mussolini: os italianos de Sao Paulo e a luta contra o fascismo, 19191945, FAPESP, Sao Paulo, 1999.

BERTONHA, João Fábio, "Emigrazione e política estera: la «diplomazia sovversiva» di Mussolini e la questione degli italiani all'estero, 1922-1945”, en Altreitalie, Turín, 2001, No 23, pp. 39-60.-

BEZZA, Bruno, Gli italiani fuori d'Italia: gli emigranti italiani nei movimienti operai dei paesi d'adozione, 1880-1940, Franco Agneli, Milano, 1983.

BISSO, Andrés, "El antifascismo latinoamericano: usos locales y continentales de un discurso europeo", en Asian Journal of Latin American Studies, Daegu, 2000, V. XXVI, pp. 91-116.

BISSO, Andrés, "El antifascismo argentino: Imagen de redención 'democrática' de la sociedad civil en la Argentina fraudulenta y militar de los años 30 y 40”, en Trabajos y Comunicaciones, La Plata, 2000, No 26-27, pp. 211-232.

BISSO, Andrés, Sociedad, politica y movilización. Cuatro recorridos bonaerenses (1932-1943), Editorial Buenos Libros, Buenos Aires, 2009.

BORDAGARAY, María Eugenia, "Luchas antifascistas y trayectorias generizadas en el movimiento libertario argentino (1936-1955)”, en Cuadernos de H Ideas, La Plata, 2013, V. VII, No 7, pp. 1-18. Disponible en: <http://perio.unlp.edu.ar/ojs/index.php/cps/article/view/2064> [Consulta: 5 de junio de 2016].

BRUTI LIBERATI, Luigi, Il Canada, l'Italia e il fascism, 1919-1945, Bonacci, Roma, 1984.

BUFFA, Norma, "Inmigración y movimiento obrero en Bahía Blanca durante la primera década del siglo XX. Sus ideologías”, en WEINBERG (director) Estudios sobre inmigración II, Universidad Nacional del Sur, Bahía Blanca, 1994, pp. 79-110.

CERNADAS, Mabel, “Inmigración y vida cotidiana en Bahía Blanca hacia 1880”, en WEINBERG (director) Estudios sobre inmigración II, Universidad Nacional del Sur, Bahía Blanca, 1994, pp. 5-77.

CERNADAS, Mabel y ORBE, Patricia, "Diarios bahienses en perspectiva: idas y vueltas en búsqueda de la pluralidad”, en CERNADAS, Mabel y ORBE, Patricia (compiladoras) Itinerarios de la prensa: cultura 
politica y representaciones en Babia Blanca durante el siglo XX, Ediuns, Bahía Blanca, 2013, pp. 23-45.

CIMATTI, Bruno, "De la 'gavilla fascista' a la Casa del Italiano. Los primeros pasos del fascismo en Bahía Blanca (1926-1927)", ponencia presentada en XV Jornadas Interescuelas/Departamentos de Historia, Universidad Nacional de la Patagonia San Juan Bosco, Comodoro Rivadavia, 2015.

CIMATTI, Roberto, "Concejales, trabajadores y militantes sindicales. Algunas observaciones sobre el núcleo dirigente del socialismo bahiense (1916-1930)”, en DEL VALLE, Laura y EBERLE, Adriana (compiladoras) Pensar e investigar el poder, Ediuns, Bahía Blanca, 2014, pp. 83-109.

CRESCIANI, Gianfranco, Fascism, Anti-fascism, and Italians in Australia, 1922-1945, Australian National University Press, Canberra, 1980.

CROCITTO, Geremia et al., Un siglo de vida de la Sociedad Italiana de Socorros Mutuos de Bahia Blanca, Palumbo Hnos., Bahía Blanca, 1982.

DE CAPRARIIS, Luca, “Fascism for export? The Rise and Eclipse of the Fasci Italiani all'Estero”, en Journal of Contemporary History, Londres, 2000, No 35, V. II, pp. 151-183.

DEVOTO, Fernando, "La experiencia mutualista italiana en la Argentina: un balance”, en DEVOTO, Fernando y MÍGUEZ, Eduardo (compiladores) Asociacionismo, trabajo e identidad étnica. Los italianos en América Latina en una perspectiva comparada, CEMLA-CSER-IEHS, Buenos Aires, 1992, pp. 169-185.

DEVOTO, Fernando, "Participación y conflictos en las sociedades italianas de socorros mutuos", en DEVOTO, Fernando y ROSOLI, Gianfausto (editores) La inmigración italiana en la Argentina, Biblos, Buenos Aires, 2000, pp. 141-164.

DEVOTO, Fernando, Historia de los italianos en la Argentina, Biblos, Buenos Aires, 2006.

GANDOLFO, Romolo, "Las sociedades italianas de socorros mutuos de Buenos Aires: cuestiones de clase y etnia dentro de una comunidad de inmigrantes, (1880-1920)", en DEVOTO, Fernando y MÍGUEZ, Eduardo (compiladores) Asociacionismo, trabajo e identidad étnica. Los italianos en América Latina en una perspectiva comparada, CEMLA-CSER-IEHS, Buenos Aires, 1992, pp. 311-332.

GONZÁLEZ CALLEJA, Eduardo, "De emigrantes a representantes de la nación en el extranjero: la política de encuadramiento partidista de los Fasci Italiani all'Estero”, en Pasado y Memoria. Revista de Historia Contemporánea, Alicante, 2012, No 11, pp. 19-39.

MONACCI, Gustavo, "Inmigración” en WEINBERG, Félix (director) Historia del sudoeste bonaerense, Plus Ultra, Buenos Aires, 1988, pp. 205-243.

MORELLI, Anne, Fascismo e antifascismo nell'emigrazione italiana in Belgio (1922-1940), Bonacci, Roma, 1987.

PASOLINI, Ricardo, "Intelectuales antifascistas y comunismo durante la década de 1930. Un recorrido posible: entre Buenos Aires y Tandil”, en Estudios Sociales, Santa Fe, 2004, V. XXVI, No 1, pp. 81-116. 
PRISLEI, Leticia, Los origenes del fascismo argentino, Edhasa, Buenos Aires, 2008.

PRISLEI, Leticia, "Redes intelectuales ante el fascismo: polémicas culturales y políticas acerca de las leyes raciales italianas y los exilios en Argentina”, en Pasado y Memoria. Revista de Historia Contemporánea, Alicante, 2012, № 11, pp. 93-113.

VECCHI, Rodrigo, "De escuadras, compases y camisas negras: el monumento a Giuseppe Garibaldi o la representación formal de los conflictos en la colectividad italiana bahiense (1927-1928)", en Discutir el canon. Tradiciones y valores en crisis, CAIA, Buenos Aires, 2003, pp. 598-599. 